\title{
Multiple sclerosis in Coloured South Africans
}

\author{
FRANCES R. AMES AND STEVEN LOUW \\ From Groote Schuur Hospital, Cape Town, South Africa
}

S U M MAR Y Detailed case histories of seven Coloured South Africans with multiple sclerosis are presented; the summary of one South African-born Indian is included. Apart from an isolated case report in 1947, this is the first time that multiple sclerosis has been reported in detail in this South African racial group. All the Coloured patients presented for the first time during the last 12 years.

Multiple sclerosis and the allied demyelinating condition neuromyelitis optica have, until recently, been uncommon in South Africa. An increased incidence in the last two decades has been documented and discussed by Bird and Kerrich (1969) and Bird and Satoyoshi (1975). All Bird's patients were white. A phenomenon of considerable interest is the rarity of the disease in black South Africans. No case of multiple sclerosis has been described among the 18629000 Africans who constitute $71.0 \%$ of the population. One 'probable' case reported by Kramer et al. (1956) was shown at necropsy by Kaufmann and Lipschitz (1962) to have a trigeminal neurofibroma. Two black patients with neuromyelitis optica have been recorded. Bird and Satoyoshi (1975) states 'one case of neuromyelitis optica in a black patient, proved at necropsy, was reported by Reef and Kaufmann (1969, personal communication)'. Hift and Moodley (1973) reported a case in an African female.

Among 2434000 Coloured South Africans who constitute $9.3 \%$ of the population one patient was reported in detail by Cochrane (1947). Among the 746000 Asiatics $(2.8 \%$ of the population) one patient is mentioned by Bird and Satoyoshi (1975) who, in discussing the few necropsy studies of White South Africans with multiple sclerosis state 'There has also been a case in a South African-born Indian (Procter and Kaufmann, 1970, personal communication)'.

The purpose of this paper is to present eight Coloured patients in whom a diagnosis of multiple sclerosis was made on the criteria established by

Address for correspondence and reprint requests: Dr Frances Ames, Head, Neurology Department, Groote Schuur Hospital, Observatory 7925, Cape Town, South Africa.

Accepted 5 February 1977
Schumacher et al. (1965). Seven patients were members of the Cape Coloured community, a population which has evolved during the past hundred years by a mixture of African negro, Xhoisan (Bushman and Hottentot), Malay, and Caucasian peoples; one was Indian. All patients were admitted at least once to Groote Schuur Hospital and were examined by other members of the Neurology Department in addition to the authors. The duration of the disease was 20 years in the Indian patient, and in the Coloured group one patient had had the disease for 12 years, two for 11 years, two for two years, and two for six months.

The cerebrospinal fluid (CSF) was examined for total protein, albumin, globulin, immunoglobulin (IgG), glucose, cell count, serology (including the Venereal Disease Research Laboratory test (VDRL), the Treponema Immobilisation test (TPI), and the Fluorescent Treponema Antibody Test (FTA)), and the Lange colloidal gold curve. Measles complement fixing antibodies were measured in the CSF and sera of six patients. HLA tissue typing was done on three patients.

The usual routine tests included full blood counts, sedimentation rate, analysis of blood chemistry on a 12 channel autoanalyser, electroencephalography, radiography of chest and skull, tests for collagen disease (in some patients), myelography in two patients, carotid angiography in two, vertebral angiography in one, lumbar pneumoencephalography in one, and brain scan in one.

\section{Case reports}

CASE 1

This 30 year old woman (FF) was first admitted to hospital in 1965 when she was 19 years old. She 
suddenly developed bilateral visual disturbance which was followed within four days by vertigo and vomiting. Examination revealed bilateral central scotomata, normal optic discs, coarse gaze nystagmus to the left, bilateral 6th nerve palsies, mild left pyramidal tract involvement of all limbs, incoordination of the left upper limb, and ataxia of gait. CSF chemistry, cells, culture, Lange curve, and serology were normal. She improved while on steroids, and after about six weeks her scotomata and brainstem signs disappeared. Two years later, after her first pregnancy she developed sudden transient weakness of both legs, and two years after this, again after pregnancy (her second) she developed transient weakness of both legs. A year later she was admitted with recurrence of weakness of both legs, hyperreflexia, bilateral extensor plantar responses, defective position and vibration sense, touch-pain sensation below T10 dermatome, and impaired coordination in her left upper and both lower limbs. She improved slowly but three months later had transient defect of vision on the left and incontinence of urine. Four years later she again developed cord involvement at midthoracic level and some weeks later right upper limb weakness. She improved slowly and during 1975 remained well. In February 1976 she developed weakness of the upper and both lower limbs, bilateral orbital pain, precipitancy of micturition, and constipation. In June 1976 she came, at our request, for assessment. She was her usual cheerful self and complained only of poor vision, precipitancy of micturition, constipation, and 'dragging' of the left leg. Examination revealed bilateral optic atrophy (visual acuity was $6 / 12$ in both eyes), generalised hyperreflexia (including a brisk jaw jerk), bilateral extensor plantar responses, defective coordination in the left upper and both lower limbs, defective vibration sense in the left lower limb, and hyperaesthesia below T10 dermatome. CSF contained albumin $0.8 \mathrm{~g} / 1$ and IgG $0.96 \mathrm{~g} / \mathrm{l}$. The Lange colloidal gold curve was 5554310000 . VDRL and FTA were negative. Measles antibodies in CSF were present to a titre of 16 and blood measles antibodies to $1 / 128$. HLA tissue type was A2, A9, BW 15.

\section{CASE 2}

This 30 year old man (DD) developed fever, malaise, and cough in July 1974, and four days later experienced a pins and needles sensation in the toes of the left foot. This extended to the umbilicus and was accompanied by numbness. Within a few days the right lower limb was similarly affected and one week later his gait became unsteady, the paraesthesiae disappeared and his left leg felt weak, both legs felt stiff and he had difficulty in initiating micturition. He was admitted in August at which time power in the lower limbs was normal but tone was increased and reflexes brisk (more so on the left), and abdominal reflexes were absent on the right. The CSF contained $0.7 \mathrm{~g} / 1$ of total protein and 6 lymphocytes per $\mathrm{mm}^{3}$. The VDRL was negative in the CSF but positive to a titre of 8 in the blood. A repeat CSF showed protein of $0.5 \mathrm{~g} / 1$ and no cells. He was discharged and given a course of penicillin as an outpatient. He was readmitted in January 1975 complaining of lumbar pain and difficulty in initiating micturition. Power was normal but tone was increased in the lower limbs with clonus on the right, generalised hyperreflexia, and absent right abdominal reflexes. VDRL was negative in CSF; blood VDRL was positive to a titre of 4 . He improved and remained well until November 1975 when he complained of pain on moving the left eye and defective vision. On examination vision was reduced to finger counting, the pupillary reflex was absent, a central scotoma was present, and the optic disc was normal. He received a course of steroids. In March 1976 he developed left retrobulbar neuritis and on admission was found to have right optic atrophy with vision reduced to finger counting at two metres, perception of light on the nasal side of the left eye, and bilaterally sluggish pupillary reflexes. His pyramidal tract signs were unchanged. He was given another course of prednisone. One week after admission visual field charting showed bilateral central scotomata and inferior loss. The CSF protein was $0.4 \mathrm{~g} / 1$, albumin $0.28 \mathrm{~g} / 1$, and $\mathrm{IgG} 0.05 \mathrm{~g} / \mathrm{l}$. Lange colloidal gold curve was 223310000 and three weeks later, after steroids 111100000 . No measles complement fixing antibodies were present in the CSF but present in the serum to a titre of 1 in 32. HLA tissue type was A11, AW33, BW 17, Bw 35. He had a history of bacterial meningitis at 3 years and epilepsy which was well controlled on phenobarbitone and phenytoin since the age of 9 years. In 1969 he had fractured his right femur, a Kirschner nail had been inserted and this was followed by infection and sequestrum formation. In 1971 right femoral sequestrectomy had been performed.

The patient was readmitted on 11 November 1976 complaining of periodic episodes (lasting a few minutes) of subjective coldness associated with clonic jerking of either the right upper or the right or left lower limbs. For one month he 
had had pain above both eyes. On examination he had bilateral optic atrophy and could count fingers with both eyes. All deep reflexes were brisk in the right upper limb and left lower limb while abdominal reflexes were present on the left but reduced on the right.

\section{CASE 3}

This 31 year old woman (MR) was admitted to a Johannesburg hospital in 1975 with a history of bilateral lower limb weakness since 1973. This had started on the right and then extended to the left over a period of three to four months. In addition she complained of precipitancy of micturition, failing vision, and poor memory. Her mother observed that she had become casual about her appearance and household duties. Examination revealed $6 / 60$ vision in both eyes, bilateral pyramidal tract involvement (more marked on the right), generalised hyperreflexia, and extensor plantar responses. The CSF was normal. Blood and CSF serology were negative. Three pneumoencephalograms showed moderately dilated ventricles with excess air in the Sylvian fissure and over the cerebellum. Brain biopsy was reported as 'normal without evidence of Alzheimer's disease or intraneuronal inclusions'. She was admitted to Groote Schuur Hospital on 1 September 1976. She gave a poor account of herself, smiled inappropriately, denied manifest incontinence, but was correctly orientated for time and place and could do simple arithmetic (she had passed Standard 2 at the age of 14 years). Vision was reduced to counting fingers at two metres, there was peripheral constriction of the visual fields, and both discs were atrophic; a rotary nystagmus was present at rest and enhanced on looking to the right. There was vertical nystagmus, a left internuclear ophthalmoplegia (incomplete left medial rectus palsy with nystagmus in the abducting eye on conjugate gaze to the right). She had pyramidal tract involvement of all limbs (weakness graded as $4 / 5$ except in the right lower limb where it was $2 / 5$ ), generalised hyperreflexia, and bilateral extensor plantar responses. Position sense was defective in the toes, vibration sense impaired below the sternum, and incoordination, dysmetria, and intention tremor present in all limbs. She could stand with support and her gait was markedly ataxic. The CSF contained $0.3 \mathrm{~g} / 1$ of protein, albumin concentration was $0.19 \mathrm{~g} / 1$, and $\mathrm{IgG}$ $0.046 \mathrm{~g} / 1$. Blood FTA was positive but all other serological tests for syphilis in blood and CSF were negative. Rubella HA1 antibodies were present to a titre of 8 in the blood but none were detected in the CSF. Measles antibodies were present to a titre of 512 in blood but none were present in CSF.

\section{CASE 4}

This 27 year old woman $(\mathrm{CPh})$ was admitted on 25 May 1976 complaining of right parietal headache for five days, numbness of the right side of the face for four days, vertigo, vomiting, numbness of the right limbs, dysarthria, ataxia, right sided 'deafness' for three days, and dysphagia for two days. Abnormal signs were confined to the nervous system. She was acutely distressed because of vertigo and vomiting. She had gaze nystagmus total right trigeminal involvement, minimal weakness of the right upper face, right palatal weakness, right pyramidal tract involvement $(4 / 5$ weakness, hyperreflexia, increased tone and absent abdominal reflexes), defect of all modalities of sensation on the right, and impaired coordination in the right limbs. She remained alert but vertiginous and during the next few days developed complete right facial weakness of lower motor neurone type, a right extensor plantar response and bilateral gaze nystagmus. Steroids were administered from 2 June 1976. Her brainstem signs began to improve but on 11 June - that is, 15 days after admission-she complained of defective vision in the left eye and within three days could barely perceive light. The pupillary reflex was sluggish and the disc was normal. Vision improved slowly and on 14 July 1976 she could perceive hand movements on the left but had developed a centro-caecal scotoma to red on the right. By 29 July she could count fingers at one metre on the left and had a right central scotoma and bilateral optic atrophy. Her other neurological abnormalities improved steadily with one shortlived relapse with left pyramidal tract signs on 12 July. On 30 July she had minimal right motor 5th and right 7 th nerve weakness, power in the limbs was normal but tone was increased. The right knee jerk was very brisk, the right plantar response extensor, coordination was defective in all limbs but more marked in the right upper limb, and gait was ataxic. She was discharged but readmitted on 17 August 1976. One week after stopping her steroids her legs became weak and speech dysarthric. She had bilateral asymmetrical weakness $(2 / 5$ on the right and $3 / 5$ on the left), bilateral extensor plantar responses, defective position and vibration sense on the left, and a right palatal weakness in addition to bilateral cerebellar signs. On 30 August she developed a right 6th nerve palsy and nystagmus in the left eye; these persisted for a month. When 
seen as an outpatient on 15 October she was ambulant but ataxic and complained only of poor vision.

On admission in May 1976 CSF was normal. On 7 June it contained total protein $0.5 \mathrm{~g} / 1$, six polymorphs and 70 lymphocytes per $\mathrm{mm}^{3}$; on 2 July, 48 lymphocytes per $\mathrm{mm}^{3}$, and on 30 July total protein of $0.5 \mathrm{~g} / 1$ and six lymphocytes per $\mathrm{mm}^{3}$ The Lange colloidal gold curve on 29 May was 2234321000 and on 8 June 1244210000 . CSF albumin was $0.3 \mathrm{~g} / 1$ and the $\operatorname{IgG} 0.084 \mathrm{~g} / 1$. FTA was negative in the CSF and 'weakly positive' in the blood. On 1 July blood rubella HA1 antibodies were present to a titre of 16 and on 7 June no measles antibodies were detected in the lowest dilution of serum tested $(1: 8)$. All other special investigations including extensive collagen studies were normal. Audiograms and brain scan were normal. She was given a prolonged course of steroids without improvement.

\section{CASE 5}

This 29 year old man (EC) was first admitted in 1965 at the age of 18 years with an acute right hemiparesis. A left carotid angiogram and CSF chemistry were normal, and he recovered within a week. In 1966 he was readmitted complaining of a generalised burning sensation. weakness of the lower limbs, and inability to recognise objects by touch. On examination he had generalised weakness (more marked on the right and in the lower limbs), defective position and vibration sense and vague touch-pain defect in all limbs, astereognosis, impaired coordination in all limbs, a wide-based gait, and positive Romberg's sign. The CSF contained $0.3 \mathrm{~g} / 1$ of protein and 13 lymphocytes per $\mathrm{mm}^{3}$. The Lange gold curve was 0011221100 . Serology and myelogram were normal. During the first week of admission he developed horizontal and vertical gaze nystagmus, tone in the lower limbs increased, and both plantar responses became extensor. At this time the CSF contained $0.3 \mathrm{~g} / 1$ of protein and 20 lymphocytes per $\mathrm{mm}^{3}$. The Lange colloidal gold curve was now 4455200000. Lumbar pneumoencephalogram done three weeks later was normal. He improved spontaneously after several months and was free of symptoms until a year later (1967) when vision in both eyes suddenly deteriorated. He could count fingers at 1.5 metres on the left and visual acuity was $6 / 60$ on the left; he had bilateral central scotomata. Bilateral optic atrophy was noted in 1971. In 1973 his legs became weaker and he developed precipitancy of micturition. He was given prednisone. He was readmitted in 1976 complaining of progressive weakness and stiffness in the lower limbs and precipitancy of micturition. On examination he had bilateral optic atrophy with central scotomata, bilateral pyramidal tract involvement more marked in the left lower limb, impaired position sense in the toes and middle three fingers of the left upper limb, impaired vibration sense in the toes, and minimal touch-pain defect below mid thighs. Coordination was defective in the left upper and both lower limbs, and his gait was ataxic. The CSF contained $0.3 \mathrm{~g} / 1$ of protein, albumin $0.14 \mathrm{~g} / 1$ and IgG $0.052 \mathrm{~g} / 1$. Lange colloidal gold curve was 1111000000 . Measles complement fixing antibodies were absent. The HLA tissue type was A3, A9, B 12, BW 17.

\section{CASE 6}

This 36 year old woman (CPet) was admitted on 27 October with a history of insidious weakness of the left leg for four years, weakness of the right leg for two years, inability to walk for three months, weakness of the left arm for two months, and later weakness of the right arm and double incontinence. On direct questioning she said that several years before her present complaints she had noticed that her left eye 'moved by itself' and two years before admission she had an episode of horizontal diplopia on gaze to the left-this lasted for a day. Abnormal signs were confined to the nervous system. She had left optic atrophy, vision was reduced to counting fingers at 1.5 metres, and there was a central scotoma. Visual acuity was $6 / 18$ on the right. There was dissociated nystagmus (coarse and rotatory) on the left with fine horizontal nystagmus on the right. There was bilateral pyramidal tract involvement (weakness about $4 / 5$ on the right and $2 / 5$ on the left, spasticity, hyperreflexia, extensor plantar responses, and absent abdominal reflexes).

The CSF contained $0.8 \mathrm{~g} / 1$ of protein and one lymphocyte per $\mathrm{mm}^{3}$. Subsequent CSF examination yielded protein levels of $0.4 \mathrm{~g} / 1$ and $0.5 \mathrm{~g} / 1$ with albumin $0.38 \mathrm{~g} / 1$ and $\mathrm{IgG} 0.09 \mathrm{~g} / 1$. Myelogram (5 November 1975) (prone and supine) was normal. Colloidal gold curves were 1223321000 (3 November), 2222100000 (11 November) and 44554200000 ( 3 December). In the CSF, the VDRL was negative and FTA weakly positive but TPI negative. Blood VDRL was positive to a titre of 2 and FTA was positive. All tests for collagen disease were negative. Measles antibodies titre in serum was $1 / 256$ and in CSF $1 / 16$. She was given a course of steroids and discharged unchanged. When seen on 17 August and November 1976 her signs were unchanged. 
CASE 7

Six years before admission this 22 year old man (SB) became blind and during a three month stay in a county hospital gradually regained vision. He remained well until the beginning of July 1970 when he developed progressive weakness of both legs-the left preceding the right by about a week. Initial 'cramping' pains were followed by paraesthesiae up to the groin. A week later paraesthesiae and weakness developed in the right upper limb and then retention of urine. He was admitted to this hospital on 24 July 1970. General examination was normal. Neurological abnormality consisted of bilateral optic atrophy (visual acuity on right was $6 / 36$ and left $6 / 24$ ) and the fields were full to confrontation. The right upper limb was weak $(2 / 5)$, both lower limbs were completely paralysed, reflexes were obtained on the right but not the left, abdominal reflexes were absent, and plantar responses unobtainable. Sensory defect to all modalities of sensation was absent below $\mathrm{C} 4$ dermatome but the left upper limb was spared. Within a few days weakness had extended to the left upper limb, grade 3 in upper motor neurone pattern. His CSF contained $0.2 \mathrm{~g} / 1$ of protein and three lymphocytes per $\mathrm{mm}^{3}$. Myelogram done on 22 June 1970 was normal. Blood serology showed VDRL positive to a titre of 8 , WR positive and Kahn test doubtful. Blood TPI was positive (July 1970). On 7 August, blood VDRL was positive to a titre of 1 in 64, WR was positive, and Kahn test doubtful. On 6 November blood VDRL was positive to a titre of 2, WR was positive, and Kahn test negative. VDRL and WR were negative in CSF. On 8 October the colloidal gold curve was 1000000000 .

During his stay in the ward, power improved in his right upper limb and his sensory level settled at T8 dermatome, but his lower limbs remained flaccid. He received several courses of antibiotics including penicillin and ampicillin.

\section{CASE 8}

This 28 year old Indian woman (MC) developed an acute right hemiplegia in her early 20s. An angiogram done at another hospital was normal and she recovered completely. In January 1958 when she was 23 years old she complained of 'dizziness' for several weeks, in May 1958 she had defective visual acuity for three weeks, in June 1959 she was dysarthric for several weeks, and in April 1962 she developed paraesthesiae of the right cheek, lips, tongue, nose, and left hand. In July 1962 a vertebral angiogram was normal.

On 1 August 1963 she awoke with dizziness, diplopia, and 'blurred' vision. On admission she had coarse nystagmus to the right and right retrobulbar neuritis. Two weeks later she complained of oscillopsia, lameness of the right hand, and precipitancy of micturition. On examination she had nystagmus to the left, minimal weakness of the right limbs, generalised hyperreflexia, and absent abdominal reflexes. (This patient's original detailed notes were lost and we were unable to contact her for follow-up).

\section{Discussion}

In South Africa we only diagnose multiple sclerosis after prolonged observation and exhaustive investigation. In the group presented here we encountered great diagnostic difficulty with $\mathrm{CPh}$. We labelled her 'brainstem encephalitis' initially because included in her plethora of abnormal signs were motor trigeminal and palatal palsies; both of these are uncommon in multiple sclerosis. In addition she had a brisk pleocytosis (6 polymorphonuclear cells and 70 lymphocytes per $\mathrm{mm}^{3}$ ) in an otherwise normal CSF. However, the remitting, relapsing course of her illness that included bilateral retrobulbar neuritis as a prominent feature made the final diagnosis of multiple sclerosis most acceptable. Another patient (SB) had a positive blood TPI but his neurological picture was not compatible with neurosyphilis.

None of our patients had any evidence of connective tissue disease, nutritional deficiency, exposure to known neurotoxic agents, Behçet's disease, or dysglobulinaemic states, all of which can produce disseminated lesions and run a remitting relapsing course.

The clinical signs are summarised in the Table. A striking feature was that every patient had optic nerve involvement that eventually progressed to atrophy. In six patients this was bilateral, and in four of them both eyes were affected simultaneously. In four patients (three of whom had bilateral involvement) optic nerve involvement was a presenting symptom. In this respect our cases resemble those in Japan.

Kuroiwa and Shibasaki (1973) in reviewing 83 Japanese patients who were collected between 1958 and 1972 stated that visual impairment was present in $77 \%$. In $64 \%$ it was present at the onset of the disease, and in about half of these it was bilateral and simultaneous. Japan has a lower prevalence of multiple sclerosis than Western countries of similar latitude in the temperate zone but, like South Africa, has shown an increase of cases in recent years (Bird and Satoyoshi, 1975). According to Shibasaki and Kuroiwa (1973) the clinical 
Table Summary of clinical signs

\begin{tabular}{|c|c|c|c|c|c|c|}
\hline Patient & Optic nerve involvement & $\begin{array}{l}\text { Pyramidal } \\
\text { tract }\end{array}$ & Cerebellum & Brain stem & $\begin{array}{l}\text { Posterior } \\
\text { column }\end{array}$ & $\begin{array}{l}\text { Spinothalamic } \\
\text { tract }\end{array}$ \\
\hline FF & $\begin{array}{l}\text { Simultaneous bilateral retrobulbar } \\
\text { neuritis (presenting symptom) }\end{array}$ & + & + & + & + & + \\
\hline DD & $\begin{array}{l}\text { Bilateral retrobulbar neuritis (four } \\
\text { months interval between left and right). } \\
\text { Appeared } 16 \text { months after myelopathy }\end{array}$ & + & - & - & + & - \\
\hline MR & $\begin{array}{l}\text { Bilateral optic atrophy (visual } \\
\text { disturbance one of early symptoms) }\end{array}$ & + & + & + & + & - \\
\hline $\mathrm{CPh}$ & $\begin{array}{l}\text { Bilateral retrobulbar neuritis (one } \\
\text { month interval between left and right). } \\
\text { Appeared two weeks after onset of } \\
\text { illness }\end{array}$ & + & + & ++ & + & + \\
\hline EC & $\begin{array}{l}\text { Simultaneous bilateral retrobulbar } \\
\text { neuritis (two years after onset of illness) }\end{array}$ & + & + & - & + & + \\
\hline CPet & Unilateral optic atrophy - early sign & ++ & - & + & - & - \\
\hline SB & $\begin{array}{l}\text { Simultaneous bilateral blindness for } \\
\text { three months. Later return of vision } \\
\text { despite opcic atrophy }\end{array}$ & ++ & - & - & + & + \\
\hline MC & $\begin{array}{l}\text { Bilateral retrobulbar neuritis five years } \\
\text { after onset of illness }\end{array}$ & + & - & + & + & - \\
\hline
\end{tabular}

Two patients (EC and MC) presented with right hemiplegia (involving the face) as the sole initial symptom.

pattern has not changed in the cases with onset before 1964 compared with those with onset after that year except that the number of patients with visual impairment was greater in the former group. The authors suggested that this might be due to the longer follow-up period.

Our study shows that there has been a small but noteworthy occurrence of multiple sclerosis in Cape Coloured patients in the last 12 years. As the aetiology of the disease is unknown, its epidemiological peculiarities merit careful scrutiny. Dean (1967), Dean and Kurtzke (1971), Bird and Kerrich (1969), and Bird and Satoyoshi (1975) have recorded and discussed the epidemiology in this country but, by and large, their patients were all white. In South Africa $70 \%$ of the population, the 18629000 Africans, appear to be immune to the disease. However, medical services in rural areas are by no means adequate and it is possible that cases of multiple sclerosis (MS) are missed. But the disease has not been reported in urban Africans and as Bird and Satoyoshi (1975) point out 'If MS existed in the African community, one would expect to see some at least of the terminal bedridden cases which form a tragic part of the MS scene, even if the early, difficult diagnosis were missed'. This apparent immunity does not appear to be due exclusively to racial factors in that American negroes do not share it. Kurland and Westlund (1954), Acheson et al. (1960), and Alter (1962) have all recorded the disease in American negroes although Beebe $e t$ al. (1967) reported a low risk of MS in negroes.

In South Africa the $\mathbf{4} 320000$ Whites are most vulnerable to the disease but less so than in most European countries. Until now the 2434000
Coloured have been virtually immune.

The racial situation in South Africa clearly lends itself to further research. There has been much speculation about the aetiological role of viruses in multiple sclerosis. The measles virus has attracted the particular attention of Adams (1972) and others. In two of the six patients in our group in whom measles complement fixation tests were done in the CSF there were raised titres of antibodies. Further detailed study of this is planned.

The claim by Koldovsky et al. (1975) and Henle et al. (1975) of the isolation of a 'multiple sclerosis associated agent' and its neutralising activity in some sera deserves further study in the different South African racial groups. Nutritional factors are also of interest and the possible role of breast feeding in promoting the growth of healthy myelin as mentioned by G. W. A. Dick (1976, personal communication) is intriguing.

\section{References}

Acheson, E. D., Bachrach, C. A., and Wright, F. M. (1960). Some comments on the relationship of the distribution of multiple sclerosis to latitude, solar radiation and other variables. Acta Psychiatrica Scandinavica (Supplement 147), 35, 132-147.

Adams, C. W. M. (1972). Research on Multiple Sclerosis. Charles C. Thomas: Springfield, Illinois.

Alter, M. (1962). Multiple sclerosis in the negro. Archives of Neurology (Chicago), 7, 83-91.

Beebe, G. W., Kurtzke, J. F., Kurland, L. T., Thomas, L., and Nagler, B. (1967). Studies on the natural history of multiple sclerosis. 3. Epidemiologic analysis of the Army experience in World War II. Neurology (Minneapolis), 17, 1-17.

Bird, A. V., and Kerrich, J. E. (1969). Multiple 
sclerosis in South Africa. South African Medical Journal, 43, 1031-1033.

Bird, A. V., and Satoyoshi, E. (1975). Comparative epidemiological studies of multiple sclerosis in South Africa and Japan. Journal of Neurology, Neurosurgery, and Psychiatry, 38, 911-918.

Cochrane, J. C. (1947). Disseminated sclerosis in a non-European female. South A frican Medical Journal, 21, 613-617.

Dean,. G. (1967). Annual incidence prevalence and mortality of multiple sclerosis in white south African born and in white immigrants to South Africa. British Medical Journal, 2, 724-730.

Dean, G., and Kurtzke, J. F. (1971). On the risk of multiple sclerosis according to age at immigration to South Africa. British Medical Journal, 3, 725729.

Henle, G., Koldovsky, U., Koldovsky, P., Henle, W., Ackerman, R., and Haase, G. (1975). Multiple sclerosis-associated agent; neutralization of the agent by human sera. Infection and Immunity, 12, $1367-1374$

Hift, W., and Moodley, T. (1973). A possible case of neuromyelitis optica in a Bantu patient. South African Medical Journal, 47, 987-988.

Kaufmann, J. C. E., and Lipschitz, R. (1962). Trigeminal neurofibroma. South African Medical Journal, 36, 872-881.

Koldovsky, U., Koldovsky, P., Henle, W., Ackerman, R., and Haase, G. (1975). Studies on a multiple sclerosis-asscciated agent: transmission to animals and some properties of the agent. Infection and Immunity, 12, 1355-1366.

Kramer, S., Lipschitz, R., and Swhwartz, M. B. (1956). Does disseminated sclerosis occur in the Bantu? South A frican Medical Journal, 30, 829-830.

Kurland, L. T., and Westlund, K. B. (1954). Epidemiologic factors in etiology and prognosis of multiple sclerosis. Annals of the New York Academy of Sciences, 58, 682-701.

Kuroiwa., Y., and Shibasaki, H. (1973). Clinical studies of multiple sclerosis in Japan. I. A current appraisal of 83 cases. Neurology (Minneapolis), 23, 609-617.

Proctor, N. S. F., and Kaufmann, J. C. E. (1970). Personal communication. Cited by Bird, A. V. and Satoyoshi, E. (1975).

Reef, H., and Kaufmann, J. C. (1969). Personal communication. Cited by Bird, A. V. and Satoyoshi, E. (1975).

Schumacher, G. A., Beebe, G., Kibler, R. F., Kurland, L. T., Kurtzke, J. F., McDowell, F., Negler, B., Sibley, W. A., Tourtellotte, W. W., and Willmon, T. L. (1965). Problem of experimental trials of therapy in multiple sclerosis: report by the panel on the evaluation of experimental trial of therapy in multiple sclerosis. Annals of the New York Academy of Sciences, 122, 552-568.

Shibasaki, H., and Kuroiwa, Y. (1973). Clinical studies of multiple sclerosis in Japan. II. Are its clinical characteristics changing? Neurology (Minneapolis), 23, 618-622. 